\title{
EVALUASI KESESUAIAN LAHAN TANAMAN PADI TADAH HUJAN PADA LAHAN KELOMPOK TANI KARYA SUBUR
}

\author{
Ida Rizkayanti, Tamaluddin Syam, Sunyoto \& Ali Kabul Mahi \\ Jurusan Agroteknologi, Fakultas Pertanian Universitas Lampung \\ Jl. Prof. Soemantri Brodjonegoro, No. 1, Bandar Lampung 35145 \\ E-mail:ida.rizkayanti@gmail.com
}

\begin{abstract}
ABSTRAK
Beras merupakan bahan pangan yang dikonsumsi hampir seluruh penduduk Indonesia. Desa Pesawaran Indah merupakan salah satu sentra sawah tadah hujan di Kabupaten Pesawaran, oleh karena itu perlu dievaluasi potensinya. Penelitian ini bertujuan untuk mengevaluasi kesesuaian lahan kualitatif dan kuantitatif dengan cara menghitung tingkat kelayakan finansial pada pertanaman padi sawah tadah hujan (Oryza sativa L.) Kelompok Tani Karya Subur di desa Pesawaran Indah Kecamatan Padang Cermin Kabupaten Pesawaran. Penelitian ini dilakukan dengan menggunakan metode survei dan pendekatan evaluasi lahan secara paralel, yaitu melakukan analisis fisik lingkungan berdasarkan kriteria fisisk Djaenuddin, dkk, (2000) dan analisis kelayakan usaha budidaya tanaman padi sawah tadah hujan dengan menilai Net Present Value (NPV), Net Benefit Cost Ratio (net B/C) dan Internal Rate Return (IRR) untuk data selama 4 musim. Berdasarkan hasil penelitian yang telah dilakukan dapat disimpulkan bahwa lahan penelitian Kelompok Tani Karya Subur di Desa Pesawran Indah Kecamatan Padang Cermin Kabupaten Pesawaran digolongkan dalam kelas kesesuaian lahan cukup sesuai dengan faktor pembatas curah hujan dan C organik (S2 wanr). Secara finansial, usaha budidaya tanaman padi sawah tadah hujan Kelompok Tani Karya Subur di Desa Pesawaran Kecamatan Padang Cermin Kabupaten Pesawaran adalah menguntungkan dan layak untuk dikembangkan. Hal ini dibuktikan dari hasil hitungan rata-rata yang menunujukkan bahwa nilai NPV Rp 26.624.204, Net B/C 2,43 dan IRR 30,85\% yang nilainya lebih besar dari suku bunga yang digunakan yaitu $15 \%$ tahun $^{-1}$.
\end{abstract}

Kata kunci : Evaluasi Kesesuian lahan, kelayakan usaha sawah tadah hujan.

\section{PENDAHULUAN}

Padi merupakan sumber karbohidrat utama bagi mayoritas penduduk dunia. Kebutuhan pangan semakin meningkat seiring dengan jumlah penduduk yang terus bertambah sehingga, untuk mencukupi kebutuhan tersebut sektor pertanian harus dapat meningkatkan produksinya. Perkembangan produksi tanaman padi (Oryza sativa L.) baik di Indonesia maupun negara lain penghasil padi terjadi setelah tahun 1960 dengan lahirnya revolusi hijau (Purnamawati, 2009). Negara produsen padi terkemuka adalah Republik Rakyat Cina (31\% dari total produksi dunia), India (20\%) dan Indonesia (9\%). Produksi padi tahun 2009 mencapai 64,33 juta ton Gabah Kering Giling (GKG). Dibandingkan produksi pada 2008, terjadi peningkatan sebanyak 4,00 juta ton atau $6,64 \%$. Produksi padi di Provinsi Lampung tahun 2010 yaitu sebesar 2,81 juta ton (GKG), meningkat 134 ribu ton dibandingkan produksi padi tahun 2009. Peningkatan produksi padi tahun 2010 disebabkan adanya kenaikan luas panen sebesar 20,19 ribu ha dan kenaikan produktivitas sebesar $0,67 \mathrm{kw} \mathrm{ha}^{-1}$ (BPS Indonesia, 2011).

Menurut Badan Pusat Statistik Kabupaten Pesawaran (2012), luas sawah tadah hujan di Kabupaten
Pesawaran adalah 34.666 ha, sedangkan di Kecamatan Padang Cermin luas sawah tadah hujannya adalah 3.476 ha. Lahan yang diteliti seluas 8 ha di Desa Pesawaran Indah. Tanaman padi sawah tadah hujan pada daerah tempat penelitian hanya ditanam secara menetap yaitu, lahan tersebut khusus ditanam padi tadah hujan jenis Varietas non hibrida yaitu Ciherang. Alasan para petani menggunakan padi Ciherang dikarenakan jenis padi ciherang lebih tahan terhadap hama wereng.

Penelitian ini bertujuan untuk menilai kesesuaian lahan kualitatif dan kuantitatif tanaman padi sawah tadah hujan (Oryza sativa L.) Kelompok Tani Karya Subur di Desa Pesawaran Indah Kecamatan Padang Cermin Kabupaten Pesawaran.

\section{METODE PENELITIAN}

Penelitian dilaksanakan pada lahan pertanaman padi (Oryza sativa L.) Kelompok Tani Karya Subur Desa Pesawaran Indah Kecamatan Padang Cermin Kabupaten Pesawaran dengan areal pertanaman padi yang diteliti seluas 8 ha. Penelitian ini dilaksanakan pada bulan April sampai Juni 2012. Bahan yang digunakan dalam penelitian adalah contoh tanah dan bahan-bahan kimia untuk analisis tana di laboratorium. Sedangkan 
peralatan yang digunakan antara lain adalah Global Positioning System (GPS), bor tanah, meteran, Munsell Soil Chart, kantung plastik, kamera digital, alat-alat tulis dan alat-alat laboratorium.

Metode yang dilakukan untuk evaluasi lahan pada penelitian ini adalah metode survei dengan menggunakan metode evaluasi lahan secara paralel yaitu melakukan evaluasi kualitatif (biofisik) dan kuantitatif (ekonomi) secara bersamaan. Evaluasi lahan kualitatif dilakukan berdasarkan Djaenuddin, dkk. (2000), sedangkan evaluasi lahan kuantitatif yaitu kelayakan finansial dengan menghitung NPV, Net B/C dan IRR.

Penelitian ini dilakukan dengan beberapa tahapan yaitu persiapan, pengumpulan data dan analisis data. Tahap Persiapan merupakan tahap studi pustaka, yaitu meneliti dan mengkaji sumber-sumber pustaka tentang keadaan lokasi penelitian sehingga memperoleh gambaran umum tentang lokasi penelitian, seperti data iklim dan karateristik lahan. Pada tahap ini dilakukan survei lapang secara kasar dan penentuan titik pengambilan contoh tanah yang mewakili secara keseluruhan berdasarkan keadaan lapang. Pada tahap pengumpulan data, data yang dikumpulkan meliputi data fisik dan data sosial ekonomi. Data fisik antara lain data fisik primer yaitu data yang diamati dan diukur langsung di lapang (drainase, bahan kasar, kedalam tanah, lereng, bahaya erosi, genangan, batuan dipermukaan dan batuan singkapan) dan data yang dianalisis di laboratorium (KTK tanah, basa-basa yang dapat dipertukarkan, $\mathrm{pH}$ tanah, C organik dan tekstur tanah), sedangkan data fisik sekunder, curah hujan dan kelembaban udara diambil 10 tahun terakhir. Data sosial ekonomi meliputi data sosial ekonomi primer (biaya pembenihan, pupuk, pertisida, peralatan, tenaga kerja dalam pengolahan tanah, penanaman, pemupukan, pengendalian gulma sampai panen dan pendapatan) yang didapat dari wawancara dengan petani dan data sosial ekonomi sekunder (data luas panen dan hasil produksi gabah).

Analisis data kesesuaian lahan kualitatif dilakukan dengan cara mencocokkan syarat tumbuh tanaman padi berdasarakan kriteria Djaenuddin, $d k k$. (2000) dengan menilai karakteristik dan kualitas lahan di lapang. Kemudian analisis kuantitatif dilakukan analisis finansial dengan menghitung nilai NPV, Net B/C ratio dan IRR (Ibrahim, 2003).

\section{HASIL DAN PEMBAHASAN}

Pada hasil analisis lahan kualitatif, penilaian kesesuaian lahan kualitatif berdasarkan kriteria biofisik untuk tanaman padi sawah tadah hujan berdasarkan pada kualitas dan karakteristik lahan yang berada di Desa
Pesawaran Indah Kecamatan Padang Cermin Kabupaten Pesawaran yang dibandingkan dengan persyaratan tumbuh tanaman padi sawah tadah hujan berdasarkan kriteria Djaenuddin, dkk. (2000). Berdasarkan hasil pengamatan dan karakteristik lahan maka kelas kesesuaian lahan untuk tanaman padi sawah tadah hujan di lokasi penelitian di masukan kedalam kelas cukup sesuai dengan faktor pembatas curah hujan dan C organik (S2 wanr). Hasil perhitungan selengkapnya tertera pada Tabel 1.

Pada Analisis kuantitatif terdiri dari biaya usahatani tanaman padi sawah tadah hujan, penerimaan, dan analisis finansial. Biaya usahatani tanaman padi sawah tadah hujan terdiri dari biaya tetap dan biaya variabel. Biaya tetap pada lahan penelitian terdiri dari biaya sewa lahan Rp 500.000 dan alat pertanian Rp 89.000. Biaya variabel atau biaya tidak tetap terdiri dari biaya benih Rp 270.000 dan biaya pupuk Rp 450.000, biaya pengolahan tanah Rp 650.000, biaya upah tenaga kerja untuk 28 orang Rp 1.365.000 dan pestisida Rp 40.000 liter $^{-1}$.

Penerimaan dari penjualan gabah kering giling pada tiap musim tanam selalu mengalami perubahan. Pada musim tanam pertama dan kedua diperoleh penerimaan rata-rata sebesar $\mathrm{Rp}$ 14.231.250 dan $\mathrm{Rp}$ 15.225.000 serta pada musim tanam ketiga dan keempat diperoleh penerimaan rata-rata sebesar $\mathrm{Rp}$ 16.278.750 dan $\mathrm{Rp}$ 18.525.000. Total penerimaan rata-rata usahatani padi selama empat musim tanam adalah sebesar $\mathrm{Rp}$. 16.065.000.

Analisis finansial dilakukan dengan menghitung nilai penerimaan bersih sekarang, nilai perbandingan antara penerimaan bersih dan biaya serta nilai tingkat pengembalian internal dengan menggunakan tingkat suku bunga yang berlaku dimasyarakat saat ini. Tingkat suku bunga yang berlaku diasumsikan sebesar $15 \%$. Berdasarkan hasil perhitungan data maka rata-rata NPV usaha padi sawah tadah hujan Kelompok Tani Karya Subur adalah Rp 26.624.024, Net B/C sebesar 2,43 dan IRR 30,85\% lebih tinggi dari tingkat suku bunga $15 \%$ sehingga layak untuk di kembangkan.

Pada kesesuaian lahan kualitatif, hasil penelitian yang telah dilakukan pada budidaya tanaman padi sawah tadah hujan baik secara langsung di lapang maupun analisis di laboratorium, maka didapat dua faktor pembatas yaitu curah hujan dan $\mathrm{C}$ organik yang masuk kedalam kelas kesesuaian lahan cukup sesuai ( $\mathrm{S} 2$ wanr). Nilai C organik pada lahan penelitian sebesar 1,12\% sehingga termasuk kedalam kelas kesesuaian lahan cukup sesuai (S2). Salah satu penyebab rendahnya kandungan $C$ organik tanah pada lahan penelitian selain terbawa oleh panen juga disebabkan oleh kurangnya 
Tabel 1. Kelas kesesuaian lahan aktual tanaman padi sawah tadah hujan (Oryza sativa L.) Desa Pesawaran Indah menurut kriteria Djaenuddin $d k k$. (2000).

\begin{tabular}{|c|c|c|c|}
\hline & $\begin{array}{c}\text { Persyaratan Penggunaan } \\
\text { (Kualitas/Karakteristik Lahan) }\end{array}$ & Nilai & Kelas Kes esuaian Lahan \\
\hline \multicolumn{4}{|c|}{ 1. Temperatur (tc) } \\
\hline & Suhu tahunan rata-rata $\left({ }^{\circ} \mathrm{C}\right)$ & 26,7 & S1 \\
\hline \multicolumn{4}{|c|}{ 2. Ketersedi aan air (wa) } \\
\hline \multicolumn{4}{|c|}{ *Musim ke-1 (April-Juli) } \\
\hline & Curah hujan (mm) bulan ke-1 & 202 & S1 \\
\hline & Curah hujan (mm) bulan ke-2 & 174,5 & S1 \\
\hline & Curah hujan (mm) bulan ke-3 & 176,1 & S1 \\
\hline & Curah hujan (mm) bulan ke-4 & 120,5 & S1 \\
\hline & \multicolumn{3}{|l|}{ *Musim ke-2 ( Oktober-Januari) } \\
\hline & Curah hujan (mm) bulan ke-1 & 203 & S1 \\
\hline & Curah hujan (mm) bulan ke-2 & 139 & S2 \\
\hline & Curah hujan (mm) bulan ke-3 & 107 & S2 \\
\hline & Curah hujan (mm) bulan ke-4 & 334 & S2 \\
\hline & \multicolumn{3}{|l|}{ *Musim ke-3 (April-Juli) } \\
\hline & Curah hujan (mm) bulan ke-1 & 276,5 & S1 \\
\hline & Curah hujan (mm) bulan ke-2 & 169,5 & S2 \\
\hline & Curah hujan (mm) bulan ke-3 & 158,9 & S2 \\
\hline & Curah hujan (mm) bulan ke-4 & 128,5 & S1 \\
\hline & \multicolumn{3}{|l|}{ *Musim ke-4 (Oktober-Januari) } \\
\hline & Curah hujan (mm) bulan ke-1 & 131 & S2 \\
\hline & Curah hujan (mm) bulan ke-2 & 143,1 & S2 \\
\hline & Curah hujan (mm) bulan ke-3 & 132 & S2 \\
\hline & Curah hujan (mm) bulan ke-4 & 150,5 & $\mathrm{~S} 2$ \\
\hline & Kelembaban $(\%)$ & 83 & S1 \\
\hline \multirow[t]{5}{*}{3.} & \multicolumn{3}{|l|}{ Media perakaran (rc) } \\
\hline & 1. Drainase & Agak terhambat & S1 \\
\hline & 2. Tekstur tanah & Agak halus & $\mathrm{S} 1$ \\
\hline & 3. Bahan kasar (\%) & 1 & S1 \\
\hline & 4. Kedalaman tanah $(\mathrm{cm})$ & $>120$ & S1 \\
\hline \multicolumn{4}{|c|}{ 4. Retensi hara (nr) } \\
\hline & 1. KTK liat $\left(\mathrm{cmol}_{\mathrm{d}} / \mathrm{kg}\right)$ & 16,04 & S1 \\
\hline & 2. Kejenuhan basa (\%) & 50,48 & $\mathrm{~S} 1$ \\
\hline & 3. $\mathrm{pH} \operatorname{tanah}\left(\mathrm{H}_{2} \mathrm{O}\right)$ & 6 & S1 \\
\hline & 4. C-organik $(\%)$ & 1,12 & S2 \\
\hline \multicolumn{4}{|c|}{ 5. Toksisitas (xc) } \\
\hline & S alinitas (dS/m) & $<2$ & S1 \\
\hline \multicolumn{4}{|c|}{ 6. Bahaya sulfidik (xs) } \\
\hline & Kedalaman sulfidik $(\mathrm{cm})$ & $>110$ & S1 \\
\hline \multirow[t]{3}{*}{7.} & Bahaya erosi (eh) & & \\
\hline & 1. Lereng $(\%)$ & 0 & S1 \\
\hline & 2. Bahaya erosi & Sanga rendah & S1 \\
\hline & Bahaya banjir (fh) & & \\
\hline & Genangan & F0 & S1 \\
\hline \multirow[t]{3}{*}{9.} & Persiapan lahan (lp) & & \\
\hline & 1. Batuan permukaan (\%) & 0 & S1 \\
\hline & 2. Singkapan batuan (\%) & 0 & S1 \\
\hline \multicolumn{3}{|c|}{ Kelas Kesesuaian Lahan } & S2 wanr \\
\hline
\end{tabular}

Keterangan : S1 = sangat sesuai, S2 = cukup sesuai, S3 = sesuai marginal. 
pemberian pupuk organik (Souri, 2001). Salah satu cara meningkatkan kandungan $\mathrm{C}$ organik pada lahan penelitian telah dilakukan dengan pemberian jerami yang dibenamkan. Selain itu untuk lebih meningkatkan C organik dapat juga dilakukan dengan pemberian pupuk kandang. Meirong, dkk. (2011), menyatakan bahwa pengaruh pemberian pupuk organik jangka panjang selama 18 tahun pada tanaman padi sawah pada kondisi subtropis meningkatkan kandungan $\mathrm{C}$ organik sebesar 19,2\% dibandingkan tanpa pupuk organik.

Pupuk organik atau bahan organik merupakan sumber nitrogen tanah yang utama, serta berperan cukup besar dalam memperbaiki sifat fisik, kimia, dan biologis tanah serta lingkungan. Bahan organik berfungsi sebagai pengikat butiran primer tanah menjadi butiran sekunder dalam pembentukan agregat yang mantap. Keadaan ini berpengaruh besar pada porositas, penyimpanan dan penyediaan air serta aerasi dan temperatur tanah. Bahan organik dengan $\mathrm{C} / \mathrm{N}$ tinggi akan memberikan pengaruh yang lebih besar pada perubahan sifat - sifat fisik tanah dibanding bahan organik yang telah terdekomposisi seperti kompos (Balai Penelitian Tanah, 2005).

Penilaian ketersediaan air dilakukan terhadap curah hujan dan kelembaban yaitu, sebagai media pelarut dan pengangkut, air hujan akan mempengaruhi komposisi kimiawi mineral-mineral penyusun tanah. Air merupakan komponen utama tanaman, maka kurangnya curah hujan akan menghambat pertumbuhan dan perkembangan tanaman. Curah hujan bulanan pada musim tanam pertama masuk ke dalam kelas kesesuaian lahan sangat sesuai (S1), sedangkan curah hujan pada musim tanam kedua ketiga dan keempat ada beberapa bulan yang termasuk ke dalam kelas cukup sesuai (S2). Curah hujan yang termasuk kedalam kelas cukup sesuai salah satunya terjadi pada musim tanam ketiga yaitu 169,5 mm bulan ${ }^{-1}$. Selanjutnya, Goto, dkk. (2008), menyatakan bahwa produksi padi di lahan sawah tadah hujan di Timur Laut Thailand bervariasi dengan perubahan yang kondisinya dipangaruhi oleh curah hujan. Lahan sawah tadah hujan di Timur Laut Thailand yang memiliki curah hujan $180 \mathrm{~mm}^{\text {bulan }}{ }^{-1}$ sudah cukup untuk tanaman padi berproduksi dengan baik.

Keterbatasan air ini dapat ditanggulangi dengan cara pembuatan lebung di sekitar areal persawahan sebagai cadangan air yang berasal dari sungai, agar dapat dialiri pada lahan pertanaman padi sawah pada saat bulan kering. Pembuatan lebung sebaiknya dibuat permanen salah satunya dengan cara di semen agar lebung menjadi kedap air sehingga air tidak dapat meresap kedalam tanah dan dapat terus digunakan pada saat bulan kering.
Pada kesesuaian lahan kuantitatif, untuk mengetahui tingkat kelayakan usahatani padi digunakan analisis NPV, Net B/C dan IRR. Dari hasil pengolahan data diperoleh nilai NPV rata-rata dari Kelompok Tani Karya Subur sebesar Rp 26.624.024 yang berarti bahwa selam 4 musim tanam usahatani padi petani akan memberikan nilai pendapatan bersih $\mathrm{Rp} 26.524 .024$. Net $\mathrm{B} / \mathrm{C}$ ratio (rasio biaya manfaat bersih) adalah perbandingan antara nilai manfaat bersih dengan biaya bersih yang diperhitungkan nilainya saat ini. Nilai penerimaan bersih dan biaya (Net B/C) yang diperoleh pada usahatani padi sawah Kelompok Tani Karya Subur yaitu sebesar 2,43. Dengan demikian dapat dikatakan bahwa usaha tani padi sawah tersebut masih layak untuk diusahakan karena nilai Net B/C lebih dari 1. Jika nilai Net B/C lebih dari 1, maka usaha tani layak untuk diusahakan.

Dari hasil perhitungan nilai IRR maka didapatkan Nilai IRR rata-rata Kelompok Tani Karya Subur sebesar $30,85 \%$, hasil lebih tinggi dari tingkat suku bunga yang gtelah ditentukan yaitu $15 \%$ tahun $^{-1}$. Meskipun kesesuaian lahan kualitatifnya termasuk kedalam kelas kesesuaian lahan S2 wanr, tetapi pada segi kelayakan finansialnya usahatani padi sawah tadah hujan di lokasi penelitian menguntungkan dan layak untuk diteruskan.

\section{KESIMPULAN}

Berdasarkan hasil penelitian yang telah dilakukan dapat disimpulkan bahwa dari hasil penilaian kualitatif lahan Kelompok Tani Karya Subur di Desa Pesawaran Indah Kecamatan Padang Cermin Kabupaten Pesawaran memiliki kelas kesesuaian lahan cukup sesuai dengan faktor pembatas curah hujan dan C organik (S2 wanr) untuk tanaman padi sawaah tadah hujan. Berdasarkan hasil penilaian kuantitatif, usaha budidaya tanaman padi sawah tadah bujan Kelompok Tani Karya Subur di Desa Pesawaran Indah Kecamatan Padang Cermin Kabupaten Pesawaran adalah menguntungkan dan layak untuk dikembangkan.

\section{DAFTAR PUSTAKA}

Badan Pusat Statistik Indonesia. 2011. Produktvitas dan Produksi Tanaman Padi Provinsi Lampung.http://www.bps.go.id/tnmn_pgn.php. Diakses tanggal 4 Mei 2011.

Badan Pusat Statistik Kabupaten Pesawaran.2012. Pesawaran Dalam Angka 2012. Badan Pusat Statistik Kabupaten Pesawaran. 374 hlm. 
Balai Penelitian Tanah dan World Agroforestry Centre. 2005. Panduan Evaluasi Kesesuaian Lahan dengan Contoh Peta Arahan Penggunaan Lahan Kabupaten Aceh Barat. Institut Pertanian Bogor. 48 hlm.

Djaenuddin, D., Marwan, H., Subagyo, H., Mulyani, A., dan Suharta, N. 2000. Kriteria Kesesuaian Lahan untuk Komoditas Pertanian. Departemen Pertanian. 264 hlm.

Goto, S., Tsuneo, K., Pisarn, K., Anan, P., Yasushi, I., Hitoshi, T., dan Toshshiro, I. 2008. Charateristics of water balance in a rainfed paddy field in Northeast Thailand. J. Paddy Water Environ 6:153-157.
Ibrahim. 2003. Studi Kelayakan Bisnis. Rineka Cipta. Jakarta. $249 \mathrm{hlm}$.

Meirong, LV., Zhongpei, Li., Yuping, Che., FX Han., Ming Liu. 2011. Soil organic, nutrient, microbial biomass, and grain yield of rice (Oryza sativa L.) after 18 year of fertilizer application to an infertile paddy soil. J. Biol Fertil Soil. 47: 777783.

Purnamawati. 2009. Penanaman Padi Sawah. Institut Pertanian Bogor. Bogor. $24 \mathrm{hlm}$.

Souri. 2001. Penggunaan Pupuk Kandang Meningkatkan Produksi Padi. Instalasi Penelitian dan Pengkajian Teknologi Pertanian Mataram. Mataram. 